\title{
Causes, Effects and Management Mechanisms of Drought Crisis in Rural and Nomadic Communities in Southeastern Iran as Perceived by Agricultural/Rural Managers and Specialist
}

\author{
Seyed Mahmood Hosseini*, Aboulqassem Sharifzadeh** and Morteza Akbari* \\ *Department of Agricultural Extension and Education College of Agricultural Economics and \\ Development, University of Tehran-Karaj-Iran, Tehran-Karaj 31587-77871, Iran \\ Telephone:+98-(0261)2818709, Email: hosseini_mah@yahoo.com \\ **Gorgan University of Agricultural Sciences and Natural Resources -Iran, \\ Gorgan 31587-77871, Iran \\ Telephone: +989125601477, E-mail: sharifsharifzadeh@gmail.com
}

KEYWORDS Drought. Crisis Management. Rural And Nomadic Communities. South-Eastern Iran. Iran. Drought Mitigation

\begin{abstract}
Iranian rural and nomadic communities living in drought-prone marginal areas with subsistence economy, seem to be most vulnerable during the occurrence of drought crisis. Various communities have their own different approaches to manage risk and crisis, including drought and other natural disasters. In the past, however, traditional communities in dry lands typically managed and protected their resources communally using their own indigenous knowledge. Under the current situation, development of various mitigation mechanisms and crisis management systems have led to optimistic visions for controlling drought and revitalizing livelihood systems of rural and nomadic communities affected by drought. A survey research was conducted to identify and analyze the causes, impacts and management mechanisms of drought crisis in rural and nomadic communities in Southeastern Iran which have severely been affected by drought during the last decade. The sample of the study encompassed 220 managers and specialists of various rural and agricultural related governmental departments, who have been extensively participated in management and mitigation of drought crisis. The instrument for data collection was a questionnaire which was validated by a panel of experts and the reliability index was established by Cronbach's coefficient. The collected data were analyzed using the Statistical Package for the Social Sciences Software. Major findings included: five components were extracted for the causes of drought vulnerability, including: socio-economic, livelihood, hydrological, agricultural, and metrological drought. Management mechanisms of drought crisis summarized in five factors, namely as: integrated water resources management, institutional capacity building, targeted supporting, systemic planning and sustainable development of agricultural and livelihood. Based on the findings and conclusions of this study, specific recommendations were made to reduce effects of drought crisis.
\end{abstract}

\section{INTRODUCTION}

The great challenge for the coming decades will be to increase food production with less water, particularly in countries with limited water resources. The effective and sustainable use of water for agriculture has become a global priority of vital importance, requiring urgent and immediate solutions in view of intensifying competition (Smith \& Munoz, 2002). It is estimated that the world contains about 1400 million $\mathrm{km}^{3}$ of

All correspondence to:

Morteza Akbari

Department of Agricultural Extension and Education, College of Agricultural Economics and Development,

University of Tehran,

Karaj 31587-77871, Iran

Telephone: +989126115241

E-mail: M62akbary@gmail.com water. Of this water, solely 35 million $\mathrm{km}^{3}(2.5 \%)$ are freshwater. The large amount of freshwater contained in ice caps, glaciers and deep in the ground, which is not easily accessible for use. The average annual rainfall overland amounts to $119000 \mathrm{~km}^{3}$, of which some $74000 \mathrm{~km}^{3}$ evaporates back into the atmosphere. The remaining $45000-$ $\mathrm{km}^{3}$ flows into lakes, reservoirs band streams or infiltrate into the ground to replenish the aquifers. Not all of these $45000 \mathrm{~km}^{3}$ are accessible for use because part of the water flows into remote rivers during the seasonal floods (FAO 2003). According to the World Disaster Report (Walter 2004), drought and famine have proven to be the deadliest disasters of the decade worldwide, accounting for at least 275,000 deaths since 1994. This was nearly half the total for all natural disasters.

Drought, as a phenomenon, has been with 
the history of humanity since time immemorial. As historical accounts would bear, early societies struggled with the impacts of drought sometimes contributing to the downfall of a civilization. Recently global warming effects and climate change are becoming definitely a major concern of humanity and one of the major reasons of drought. In modern societies, despite the dramatic advances brought by modern technology, they have not actually provided clear answers to one of nature's debilitating calamities. Scientists consider drought as a temporary climatic aberration, which has a recurring feature that occurs in high as well as low rainfall areas. It is one of the most complex and least understood of all natural hazards, affecting more people than any other hazard (Hagman 1984). Contrasted to other natural hazards like floods, earthquakes, and hurricanes, the damage brought by drought is usually non-structural but spread over larger geographical areas. Its effect accumulates slowly over a considerable period of time and lingers on for years. Since its onset and end, as is its severity, is difficult to determine, people generally are not fully aware that they are in the midst of such an event. Drought therefore is known as creeping phenomenon, that is a normal part of climate for virtually all regions of the world; it results in serious economic, social, and environmental impacts that is complex to understand and much more difficult to anticipate (Wilhite 2000).

Drought is an insidious hazard of nature. It originates from a deficiency of precipitation over an extended period of time, usually a season or more. This deficiency results in a water shortage for some activity, group, or environmental sector. Drought severity is dependent not only on the duration, intensity and spatial extent of a specific drought episode, but also on the demands made by human activities and vegetation on a specific region's water supply.

There is not an acceptable and clear definition about drought. There is a need for different definitions (Wilhite \& Glantz 1985). The particular problem under study, the data availability and the climatic and regional characteristics are among the factors influencing the choice of event definition. Wilhite and Glantz (1985) found more than 150 published definitions of drought, which might be classified in a number of ways. Some of the most common drought definitions are summarized in Tate and Gustard (2000), Demuth and Bakenhus (1994) and Dracup et al. (1980) and Wilhite and Glantz (1985).
Drought is a complex physical and social process of widespread significance (American Meteorological Society, 2003; Owens et al., 2003). The most commonly used drought definitions, which have been applied in the current study, are based on meteorological, agricultural, hydrological, and socio-economic droughts (Wilhite and Glantz, 1985). Meteorological drought is often defined by a period of substantially diminished precipitation duration and/or intensity. Agricultural drought occurs when soil moisture is inadequate to meet the needs of a particular crop at a particular time. Hydrological drought refers to deficiencies in surface and subsurface water supplies. Socioeconomic drought occurs when physical water shortages start to affect the health, well-being, and quality of life of the people, or when drought starts to affect the supply and demand of an economic product (Wilhite and Glantz 1985; Zamani et al. 2006; MoghaddasFarimani and Hosseini 2004).

At the socio economic level, vulnerability to drought is resulted from a series of complex, multiple, and inter-related causes. Care must be taken to distinguish indicators of increased vulnerability from its assumed underlying causes. However, vulnerability itself contributes to such causes. The complex reality originating from these diverse concepts, therefore, suggest that in addressing solutions to mitigate drought, a comprehensive and systemic approach is needed not only to understand the causes, effects and management mechanisms of drought crisis, but also to select and design an appropriate approach based on location-specific circumstances.

The impacts of drought are largely nonstructural and spread over a larger geographical area than are damages from other natural hazards. The nonstructural characteristic of drought impacts has certainly hindered the development of accurate, reliable, and timely estimates of severity (Sabet-rafter et al. 1999; Sivakumar and White 2002).

Iran, located in the dry and drought-prone area of the Middle-East, has been continually affected by droughts. A severe drought which has been unparalleled during the last 30 years, seriously affected 18 of the country's 28 provinces, mostly in Southeastern and central Iran, from 1998 to 2003. This drought has continued since then in the study area, namely, the provinces of: Sistan - Baluchistan, Southern Khorasan and Kerman, affecting all aspects of socio- economic 
life and has seriously caused damages to environment and natural resources.

A recent study among Iranian farmers revealed that a small percentage of farmers facing drought perceived more resource gains than losses (Zarafshani et al. 2005). Almost all farmers had lost material resources; the gains mainly concerned personal and social resources, such as knowledge, patience, hope, and strengthened social ties. Another vulnerability assessment of drought showed that some people even welcomed drought as an event that supports societal values, such as group coherence, and because it suspended the necessity to undertake tiring fieldwork, whilst food provision was secured thanks to food aid programs (Kromker and Mosler 1998). Consequently, they did not necessarily regard drought as a threat. This is in line with results of general stress research, which showed that stressful situations can lead to a strengthening of social ties and an increase in feelings of personal mastery (Aneshensel 1996). Such results merit further investigation, but support the notion that key in understanding the psychological consequences of drought is how people cope, what the effects of these coping efforts are in terms of perceived net resource loss or gain, and hence whether people perceive drought as a loss or a gain situation.

According to the results of some studies (Scones 2001; Morten and Sear 2001; Morten et al. 2002), there were different quality and quantity of drought vulnerability from country to country and it perceived a dynamic salutes.

Barton et al. (2001) showed that some factors such as, nation, race, climates, social sta-tues, gender, and age influenced on vulnerability to drought; in addition, other factors, such as: political, economical and social infrastructures can be effective in these situations. Global and regional issues (e.g., wars, epidemic disease ...) can affect vulnerability to drought. Also, factors such as: population growth, social race, drought nature, migration and settlement patterns, degree of economic development, health and sanitary, capacity to cope with drought, information analysis and indicator delineate were identified as affecting the vulnerability to drought (DPIRP 1997; Kinsely et al. 1998; Cole 1989; Bush 1995; Blench and Marriage 1998). Regarding literature review, vulnerability causes can be summarized as: undeveloped infrastructure, lack of facilities, weak authority, lack of communication with macro political and economical systems, ineffective markets, lack of social benefits, and institutional supports (Barton et al. 2001; Voget and Somma 2000; Lorena Kenny 2002). In addition, high population growth, urban development, desert intensity, and deforestation are factors that intensify drought phenomena. Undesirable conditions of rural and nomadic communities in poor and marginal areas, which are described with low income, livelihood dependency on rain and natural resources, unavailability of appropriate technology, lack of infrastructure (e.g. road, water, energy...) supportive facilities and lack of informative and awareness systems, can be intensify vulnerability in disasters, especially in droughts.

Considering the negative and unwanted impacts of drought and the geographic situation vulnerability of Iranian society especially its rural and nomadic communities, there is a need to design purposeful, comprehensive/systemic mechanisms to cope with drought impacts (Kourdovani 2000; Mogadas-Farimani and Hosseini 2004; Sabet-Rafter et al. 1999; Nasajizadeh 2000). The first step in such a process is to obtain appropriate, up to date, relevant, exact knowledge and perception of the people involved drought phenomena; and understanding its contexts, causes, interactions, and impacts. And the next step then would be identification of affective policies, approaches, and mechanisms for decision making and plans to cope with this phenomenon and reduce its impacts (Nahavanidi-pour 1999; Kourdovani 2000; Rahmanian 1999, Khazaneh-dari et al. 1999; Salamat 1999).

Drought preparedness and management are effective strategies to reduce risks and therefore the impacts associated with droughts. Preparedness for drought necessitates greater institutional capacity at all levels of government and more efficient coordination between different levels of government. Preparedness also implies increasing the coping capacity of individuals and communities to deal with drought events (Sivakumar and White 2002).

\section{Purpose and Objectives}

The main purpose of the study was to investigate causes, effects and management mechanisms of drought crisis, in rural and nomadic communities, in Southeastern Iran. The specific objectives were: 
Identifying and analyzing root causes of rural and nomadic communities vulnerability;

- Identifying and analyzing drought effects and impacts;

- investigating the causes of vulnerability regarding hydrological, agricultural, metrological, and socio-economic drought;

- Explaining a diagram model for conducting the process of drought crisis management.

\section{METHODS AND PROCEDURES}

This survey study was conducted to analyze causes, effects and management mechanisms of drought crisis, in rural and nomadic communities in Southeastern Iran. The population consisted of 220 people who were directly and extensively engaged in the process of drought management/ mitigation throughout the various stages of its occurrence in Southeastern Iran. These included extension managers/specialist and agricultural natural resource specialists working in: Provincial Agricultural Extension offices, Natural Resources Department, Regional Water Management Department, Nomadic Affairs Department, and Agricultural Bank in the provinces of Kerman, Sistan-Baluchistan, and Southern Khorasan. The reasons that these provinces were selected for the study were the severity of drought crisis during the years before the study was began and the diversity of the rural and especially nomadic communities in these provinces, who hold and manage a wide variety of farming and nomadic production systems, each being affected differently by drought. The survey was performed through census. The frame was obtained from the provincial offices of the related departments in each province. A questionnaire was developed to explore causes, effects and management mechanisms of drought crisis. It was based, partially, on the findings and the results of the first qualitative phase of the study. Actually, this study was a two-phased qualitative and quantitative design as a joint research project of the Ministry of the Agricultural Jihad and the University of Tehran. The results of the qualitative phase have been given in a separate report. In the qualitative phase a wide groups of managers and specialists and also farmers and nomads were interviewed through semi-structured and in-depth interviews. Besides the findings of qualitative phase an extensive literature review was conducted to develop the questionnaire's items. The questionnaire covered these parts: drought causes (32 items), drought effects and impacts (25 items), and drought management mechanisms (35 items). The extent of importance of drought causes, effects and impact, and drought management mechanisms were measured on a five-point, Likert scale which ranged from 1 (not important) to 5 (extremely important). The validity (face and content) of the questionnaire was established using a panel of experts consisting of university faculty members in the departments of Agricultural Extension and Education, Agronomy, Irrigation Management in Tehran University, and specialist of various related Departments in the Ministry of Agricultural Jihad. A pilot test was conducted to determine the questionnaire's reliability (Cronbach's Alpha $=0.72,0.76$, and 0.81 for causes, effects and management mechanisms of drought crisis, respectively). After the initial mailing and two follow-ups (calling and sending another copy of the instrument), a total of 211 respondents returned the questionnaires. (Return rate 92\%).

Collected data were analyzed using the Statistical Package for the Social Sciences (SPSS). Appropriate statistical procedures (explanatory factor analysis) for analyzing were used.

\section{RESULTS}

To identify the causes, effects, and management mechanisms of drought crisis in Iranian rural and nomadic communities, the factor analysis was employed to summarize the variables of the research to a smaller quantity and to determine the effect of each of the variables to confine the factors.

\section{A: Factor Analysis of Basic Causes of Vulnerability to Drought in Rural and Nomadic Communities}

A series of exploratory factor analyses (SPSS 11.5) were conducted using the 32 variables identified as causes, with Varimax as a rotation method and Eigen values more than 1 as a cut-off point for the number of factors extracted. It was revealed that the internal coherence of the data was appropriate $(\mathrm{KMO}=0.811$ for vulnerability) and Bartlett's statistical data was at 0.01 level significant (900.24). There were five factors, according to Kaiser Criteria, as perceived by respondents, that their Eigen values were extracted more than 1 (Table 1). 
As viewed by the respondents, analyses of the causes of vulnerabilities in the rural and nomadic communities, eventually resulted in the selection of four factor solutions based on all of the 32 initial variables. These factors accounted for a total of 88 percent of the total variance explained by the model.

The first factor- 32.42 percent of the total variance explained, comprising the following three variables as important effective factors included the following eleven variables, as important drought causes: Lack of strategic and comprehensive drought plans; under- developed infrastructures in rural/nomadic communities; ineffective market systems for inputs supply and marketing the commodities, low investment and uneconomical capital expenditure systems in rural/ nomadic communities, lack of cooperation among public and private sectors and interruption of traditional systems, lack of people's participation in drought management planning; political and social isolation of rural and nomadic communities; ineffective modern and traditional social organizations to cope with drought in rural and nomadic communities, emphasis on short time versus long time facility provisions; widespread chronic poverty in rural and nomadic communities; and the current special characteristic of Iranian rural/nomadic population (such as high birth rate, migration and immigration, and aging). This factor was named "Socio-Economic Drought" . Loadings range from 0.97 to 0.99 .

The second factor- 19.3 percent of the total variance explained, comprising the following seven variables as important drought causes; traditional animal husbandry and unawareness of modern practices; lack of sustainable occupational and employment opportunities in rural/nomadic communities; ineffective and inappropriate public services and facilities in the rural/nomadic educational, insurance, and health systems; lack of resource diversity along with increasing rate of human and natural resource erosion; unclear and ambiguous land and pasture ownership systems; inappropriate consumption patterns and widespread urban nutrition patterns in rural/nomadic communities; and low access to modern agricultural inputs and technologies. This factor was named "Livelihood Drought". Loadings range from 0.90 to 0.98 .

The Third factor- 17.79 percent of the total variance explained, comprising the following six variables as important drought causes: Water resource shortages, lack of appropriate facilities and infrastructures for water reservation; unsustainable water network systems; lack of appropriate mechanisms for reconstruction and optimization existing water networks and resources; inappropriate water usage and high rates of water wastes; and water pollution. This factor was named "Hydrological Drought". Loadings range from 0.94 to 0.99 .

The fourth factor- 10 percent of the total variance explained, comprising the following four variables were; inappropriate institutions for irrigation and drainage systems, such as water user associations; insufficient knowledge and skills of peoples and lack of appropriate technologies in water resource management in agricultural and nomadic sectors; low access to aridity- resistant seeds and ineffective extension and education programs in water management. This factor was named "Agricultural Drought". Loadings range from 0.85 to 0.97 .

The fifth Factor- 9 percent of the total variance explained, comprising the following four variables: being located in arid and semi-arid areas, irregular distribution of rainfall and low precipitation; high temperature variation, evaporation and transpiration; and lack of data based and modern weather alarming systems. This factor was named "Metrological Drought". Loadings range from 0.81 to 0.92 .

Table 1: The extracted determinants along with Eigen values, variance percentage and the cumulative variance percentage

\begin{tabular}{lccc}
\hline Drought causes & $\begin{array}{c}\text { Eigen } \\
\text { value }\end{array}$ & $\begin{array}{c}\text { The variance percentage of } \\
\text { the Eigen values }\end{array}$ & $\begin{array}{c}\text { Cumulative variance } \\
\text { percentage }\end{array}$ \\
\hline Socio-economic drought & 11.23 & 32.422 & 32.422 \\
Livelihood drought & 6.559 & 19.291 & 51.713 \\
Hydrological drought & 6.048 & 17.787 & 69.05 \\
Agricultural drought & 3.411 & 10.033 & 79.533 \\
Metrological drought & 3.018 & 8.876 & 88.409 \\
\hline
\end{tabular}




\section{B: Factor Analysis of Drought Effects and Impacts}

The results of factor analysis of drought effects and impacts revealed that the internal coherence of the data were appropriate $(\mathrm{KMO}=0.835)$ and Bartlett's statistical data was at 0.01 level significant (2389.811). According to Kaiser's criteria, the results showed that drought have had four effects, that their Eigen values were extracted more than 1 (Table 2).

The results of explanatory factor analysis of drought effects and impacts extracted four principal components called, EnvironmentalEcological impacts $(28.3 \%)$, LivelihoodEconomical impacts (23.28\%), Social impacts $(22.73 \%)$ and Psychological impacts (10.46\%). These factors, totally explained $84.76 \%$ variances of analyzed effects and impacts.

\section{C: Analysis of Drought Management Mechanisms}

At the third step, the drought management mechanisms in rural/nomadic communities were analyzed. The results showed that data were appropriate and $\mathrm{KMO}=0.739$ and Bartlett's statistical data was at 0.01 level significant (774.495). According to Kaiser Criteria, the results showed that five factors explained 75.8 percent of variance of drought management mechanisms, which their Eigen values were more than 1 (Table3).

At the third step, using the factor analysis method, 35 identified drought management mechanisms were categorized into five factors, namely as: integrated water resources management, institutional capacity building, targeted supporting, systemic planning, and sustainable development of agricultural and rural nomadic livelihood systems.

Factor $1-24.98$ percent of the total variance explained, comprising the following three variables as important effective mechanisms. This factor was named "Integrated Water Resources Management". This factor included nine mechanisms, loadings range from 0.88 to 0.98 .

Factor 2 - 17.97 percent of the total variance explained. This factor was named "Institutional Capacity Building". This factor consisted of seven mechanisms loadings range from 0.89 to 0.99 .

Factor 3 - 14.23 percent of the total variance explained. This factor was named "Targeted Supporting". Loadings range from 0.82 to 0.98 which consisted of six mechanisms.

Factor 4 - 10.93 percent of the total variance explained. This factor was named "Systemic Planning". This factor included seven mechanisms, loadings range from 0.65 to 0.82 .

Factor 5 - 7.77 percent of the total variance explained. This factor was named "Sustainable

Table 2: The extracted determinants along with the Eigen values, variance percentage and the cumulative variance percentage: Effects and impacts of drought

\begin{tabular}{lccc}
\hline Impacts & $\begin{array}{l}\text { Eigen } \\
\text { value }\end{array}$ & $\begin{array}{c}\text { The variance percentage } \\
\text { of the Eigen values }\end{array}$ & $\begin{array}{c}\text { Cumulative variance } \\
\text { percentage }\end{array}$ \\
\hline Environmental- Ecological & 7.638 & 28.290 & 28.290 \\
Livelihood - Economical & 6.284 & 23.276 & 51.566 \\
Social & 6.138 & 23.732 & 74.298 \\
Psychological & 2.823 & 10.456 & 84.754 \\
\hline
\end{tabular}

Table 3: The extracted determinants along with the Eigen values, variance percentage and the cumulative variance percentage: Drought management mechanisms

\begin{tabular}{llcc}
\hline Drought Management Mechanisms & $\begin{array}{l}\text { Eigen } \\
\text { value }\end{array}$ & $\begin{array}{c}\text { The variance percentage } \\
\text { of the Eigen values }\end{array}$ & $\begin{array}{c}\text { Cumulative variance } \\
\text { percentage }\end{array}$ \\
\hline Environmental- Ecological & 7.638 & 28.290 & 28.290 \\
Livelihood - Economical & 6.284 & 23.276 & 51.566 \\
Social & 6.138 & 23.732 & 74.298 \\
Psychological & 2.823 & 10.456 & 84.754 \\
Integrated water resources management & 8.06 & 23.4 & 24.98 \\
Institutional capacity building & 6.29 & 17.97 & 42.95 \\
Targeted supporting & 4.98 & 14.23 & 57.18 \\
Systemic planning & 3.83 & 10.93 & 68.11 \\
Sustainable development of agricultural and & 2.72 & 7.77 & 75.89 \\
$\quad$ rural nomadic livelihood systems & & & \\
\hline
\end{tabular}


Development of Agricultural and Rural Nomadic Livelihood Systems". This factor included six mechanisms, loadings range from 0.59 to 0.77 .

In general, these factors explained $75.9 \%$ variances of the analyzed drought management mechanisms in Southeastern Iran.

\section{CONCLUSION AND RECOMMENDATIONS}

The great challenge for the coming decades will be to increase food production with less water, particularly in the countries with limited water resources (such as Iran). The effective and sustainable use of water for agriculture has become a global priority of vital importance, requiring urgent and immediate solutions in view of intensifying competition (Smith and Munoz 2002).

Drought is a pervasive natural hazard that is a normal part of the climate of virtually all countries, especially, those counties that are located in dry and semi-dry areas. It should not be viewed as merely a physical phenomenon. Rather, drought is the result of interplay between a natural event and the demand placed on water and other natural resources by human-use systems. These systems can significantly exacerbate the impacts of drought through the unsustainable use of natural resources. Drought can inflict considerable impacts and hardship on societies. The impacts of droughts have demonstrated this fact again and again over the last ten years in the study area in Iran. Drought illustrates in innumerable ways the vulnerability of economic, social, political, and environmental systems to a variable climate. It also illustrates the dependencies that exist between systems, reinforcing the need for improved coordination within and between levels of government.

The economic, social, environmental, and psychological impacts of drought are the product of both the natural event (i.e., meteorological drought or precipitation deficiencies over an extended period of time) and the vulnerability of society to these periods of precipitation deficiencies. Expressed another way, the impacts of drought are determined not only by the frequency and intensity of meteorological drought but also by the number of people at risk and their degree of risk. Increasing and shifting population, changing trends and patterns of water use, institutional fragmentation, nonsustainable natural resources management policies, and growing environmental awareness and concern, all define a future where water will continue to be a primary source of conflict and controversy. Demand for water and other shared natural resources is increasing society's vulnerability to water supply interruptions caused by drought. As a result, future droughts can be expected to have greater impacts, with or without any increase in the frequency and intensity of meteorological drought (Wilhite 2000).

In the case of drought, two types of coping have been well investigated (Zamani et al. 2006). First are agricultural adjustments, most commonly the sale of livestock, early sowing of seeds, herds' diversification, plant protection, purchasing of forage, investment in shallow or deep tube wells, and cultivating more water-efficient crops (Blench and Marriage 1999; Keenan and Krannig 1997; MacDonnel et al. 1995; Mortimor and Adams 2001; Owens et al. 2003; Skoufias 2003). Second are economic adjustments (Campbell 1990; Hanson and Weltzin 2000; MacDonnel et al. 1995; Mortimor and Adams 2001; Owens et al. 2003; Rockstrom 2003; Young 1995), which show evidence for resource loss cycles. A literature review of economic coping behavior of African and Asian rural households facing famine as a consequence of drought (Corbett 1988) showed that risks to food security are frequently anticipated and carefully planned. Economic coping strategies relate to asset management. During noncrisis years, two sorts of assets are acquired. First are a form of saving and self-insurance, such as small stock and jewelry, which can be liquidated in times of crisis. Second are assets that play key roles in production and income generation, such as oxen and land, which are more risky and less liquid.

Public intervention in implementing adaptation measures and policies for managing crisis, such as drought, climate change and so on, encouraged and facilitated by the international community, falls into five categories, including (1) providing information and advice, (2) providing guidance and training, (3) promoting adaptation measures, (4) mandating adaptation, and (5) institutionalizing adaptation capacity and policy (Yohe et al. 2007).

Drought crises management, is systemic process, complex, and multi-dimensions, like his nature, and need to be strategic planning and operational schematization in long and short time periods, which complete in the county, states, regions, and even global areas. In addition, 
drought crises management must be drawn based on low (operational) levels, situational conditions, and participatory approaches and flexibility; in addition, encompass ecological, economical, social, and cultural knowledge. However, in many countries of the world there is no policy directly related to drought and when this phenomenon occurs, they ratify the program of the drought (Wilhite 1997). Countries have often reacted to drought by providing assistance, essentially on an ad hoc basis, as it is the case for other natural disasters. However, such assistance is not considered as a right of the affected population on one hand, and there exists no clear and explicit regulations on the issue on the other. The activities are also often fragmented between several institutions, with no or limited coordination. With time, this way of doing has become a de facto policy on crisis management, with all its limitations and drawbacks (Bazza 2001).

To overcome these limitations, a new vision is needed with a policy that focuses on prior preparedness, with a close linkage between regular development programs and drought mitigation. The policy would also address response to drought in a manner that profits sustainable development and management of natural resources. At the level of each country, it is recommended to establish an integrated national policy that focuses on the key sectors, which may differ from one country to another. The same approach would apply at the level of local governments or communities. Another characteristic of the policy is that it should link the different levels (government, local authorities, communities, etc.) and accommodate for good coordination of drought management.

Based on the results of this research, management mechanisms of drought crisis included 35 variables which were categorized into five factors, namely: targeted supporting, institutional capacity buildings, integrated water resource management, systemic planning, and sustainable development of agriculture and livelihood system (figure 1). Integrated water resources management is one of the critical mechanisms to conserve water for drought times. Enactment of effective laws and regulations for water conservation by private and governmental organizations are important in the case of institutional capacity building. In addition, targeting governmental supports can empower more vulnerable rural and nomadic communities, especially in disaster times, so that they can cope with the multiple effects of the disaster. Although, allocated credits and recourses are not sufficient, however at the initial stages of drought, their targeting to the most vulnerable communities can be effective.

Drought crisis management should be based on an integrated, comprehensive, systemic, pluralistic, participative and network-oriented strategy, recognizing and embracing all stakeholders, beneficiaries and clients. In fact, this process needs to recognize several interrelated causes of drought as complex phenomenon, including agricultural drought, hydrological drought, metrological drought, livelihood drought and socio-economic drought. Also, effective drought crisis management needs to explain appropriate decisions for reducing effects and impacts of drought in livelihood- economical, environmental- ecological and psychological dimensions (Fig. 1).

Although drought mitigation, necessitates sustainable management system (Mir-Abolghasemi 2000), however, the assessment of drought polices in Southeastern Iran indicates that drought management policies are mainly based on hasty and defective decisions during the crisis (Khazaneh-Dari et al. 1999).

Drought management programs cannot be effective, unless rural and nomadic communities have a voice in the planning and implementation of schemes. If stockholders involved in drought plans, it had transformed vulnerability into strength, hazards into productive resources and had improved capacities (Fig. 3), as a result, vulnerability to drought reduced. Education can be increased knowledge of people in drought prevention and empower them in order to participate in operational phases (Fig. 2).

Creating a national interagency task force with the authority to develop and implement an integrated national drought policy and plan would represent an important first step. The task force must be developing the objectives of a national policy in concern with extensive public involvement. This policy should promote the concept of risk and crisis management, although it cannot ignore the need for government assistance during extended periods of severe drought. However, this assistance must be consistent with national policy. The policy should promote self-reliance while at the same time protecting the natural and agricultural resource base. The interagency task force should coordinate the drought-related 


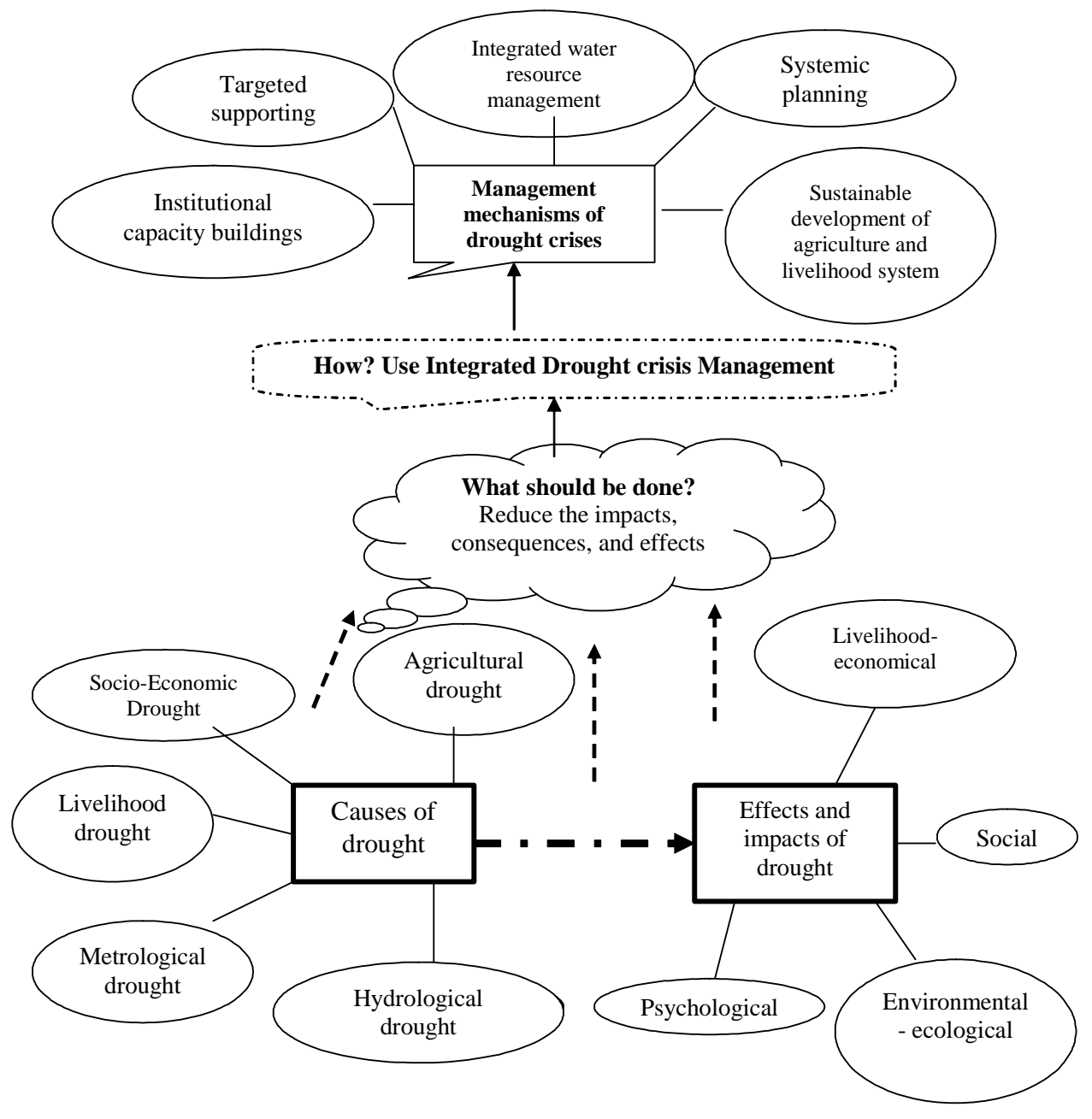

Fig. 1. Causes, effects and management mechanisms of drought crisis

activities of the national government (i.e., forecasting, monitoring, impact assessment, response and recovery, and planning). This national policy should also incorporate incentives for all drought-prone provinces to develop plans that promote a more proactive, anticipatory approach to drought management (Fig. 3).

A critical component of a national drought policy and plan is an integrated national climate monitoring system to continuously track climatic conditions and anomalies and project water availability. Some components of such a system are already in place in Iran but divided among many provincial and national agencies. This monitoring system would provide the basis for the early detection of drought and other extreme climatic events, enabling planners, natural resource managers, and others to make more informed and timely decisions. The relatively small investment required to develop and maintain this system is justified given the large benefits that would accrue through a reduction of impacts associated with droughts, floods, and other climate-related events.

Ideally, interventions should first act to prevent resource loss at the community level, in particular by raising community awareness and 


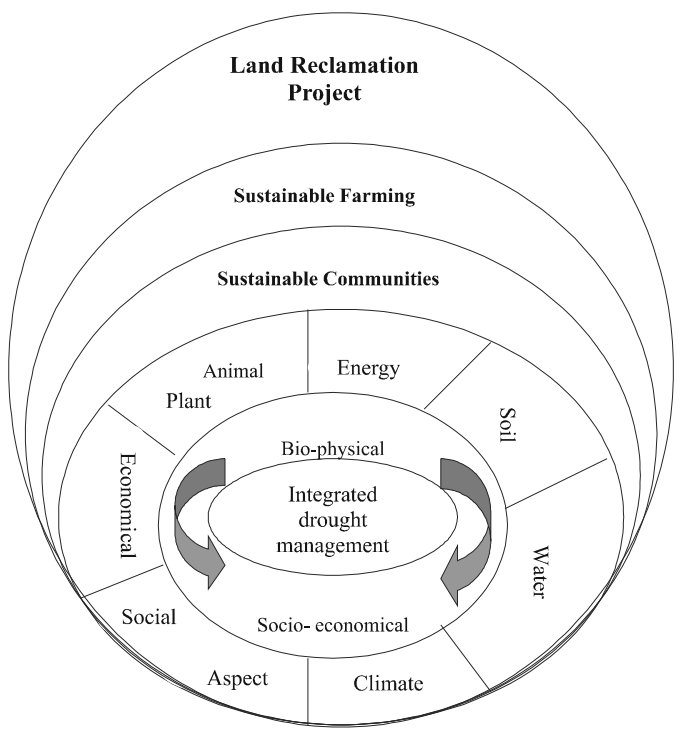

Fig. 2. A Framework for Integrated Drought Management (Seely 1999)

by developing community strategies (Zamani et al. 2006). For example, by establishing cooperatives for efficient use of water, farmers can be encouraged to plant more resistant crops and make better use of their water resources. Farmers' and tribal cooperatives can pool resources from government or non-government agencies or even from private donors, such as farm elites. It is clearly most effective to foster community preparedness before community resources are under direct strain.
Because of the confusion associated with the definition of drought and the fact that different people often have different perceptions of it, its onset is often unnoticed and its impacts are not detected on time. As a result, reaction to drought is usually late, resulting in greater losses and hardships, and making the cost of emergency and recovery even higher. This situation can be avoided only through well planned monitoring of drought, according to clear and well-defined criteria, applied by trained personnel. Drought monitoring would also serve as the basis for response to which it would be closely linked. Both monitoring and response are to be coordinated by a single agency, under the supervision of a high authority (Bazza 2001).

In general, preparation, adjustment, and adaptation strategies towards drought have been studied on the household, the community, and the national level. Much is known concerning, for example, economic behavior on these different levels and its effect on material and energy resources. What is typically missing is insight into personal consequences, such as consequences for social and personal resources, and the interaction between individual reactions and other ecological systems. For example, the study by Campbell (1999) showed how macroeconomic developments created new opportunities. It also showed how some people were able to profit from these opportunities, and others were not, based on specific structural characteristics. It would be interesting to investigate personal differences in a more psychological manner, for example, which

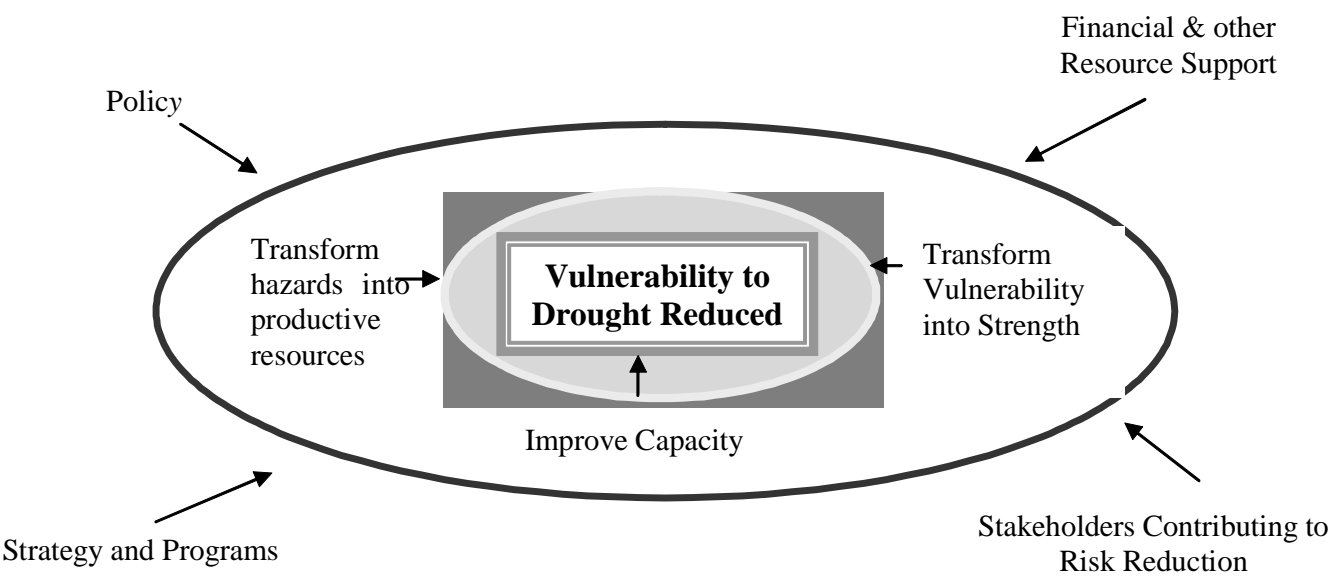

Fig. 3. Conceptual framework to reduce society's vulnerability to Drought, Unganai (2004) 
recognizes new opportunities, and is motivated to seize them.

At last, lessons learned from previous drought response attempts in Iran, need to be documented, evaluated, and shared with all levels of government through post-drought audits.

\section{REFERENCES}

American Meteorological Society 2003. Meteorological Drought, Policy statement. (Available online at:) http:// www.ametsoc.org.

Aneshensel CS 1996. Consequences of psychosocial stress: the universe of stress outcomes. In: HB Kaplan (Ed.): Psychosocial Stress; Perspectives on Structure, Theory, Life-course, and Methods, New York: Academic, pp. 111-136.

Barton D, Morton J, Hendy C 2001. Drought Contingency Planning for Pastoral Livelihoods. NRI Policy Series 15 .

Bazza M 2001. Inferences of a Drought Mitigation Action Plan. Food and Agriculture Organization of the United Nations - FAO. Regional Office for the Near East Aleppo, Syria 27-31 May 2001

Blench R, Marriage Z 1998. Drought and livestock in semi-arid Africa and the Near East. Introductory essay with annotated bibliography. Draft Prepared for circulation at the workshop 'Lessons for drought contingency planning in the pastoral and agropastoral livestock sectors'.

Blench R, Marriage Z 1999. Drought and Livestock in Semi-arid Africa and South-West Asia, London: Overseas Development Institute.

Bush J 1995. The role of food aid in drought and recovery: Oxfam's North Turkana (Kenya) drought relief program, 1992-94. Disasters, 19(3): 247-259.

Campbell DJ 1990. Strategies for Coping with Severe Food Deficits in Rural Africa: A Review of the Literature. Food and Food Ways, 4(2): 143-162.

Cole R 1989. Measuring Drought and drought impact in the Red Sea Province, Sudan. Oxfam Research Papers 2. Sudan: Oxfam.

Corbett J 1988. Famine and Household Coping Strategies. World Development, 16(9): 1099-1112.

DPIRP 1997. Drought Preparedness Intervention \& Recovery Program (DPIRP) in arid lands of Kenya. Drought Monitoring Bulletin - August 1997.

Food and Agriculture Organization (FAO) 2003. World water resources. [Available online at:] http:// www.fao.org/ documents/ show_Cdr. Asp? url_file=/ docrep $1005 / \mathrm{y} 3918 \mathrm{e} / \mathrm{y} 3918 \mathrm{e} 01 . \mathrm{htm}$.

Hagman G 1984. Prevention Better than Cure: Report on Human and Natural Disasters in the Third World, Stockholm: Swedish Red Cross.

Hanson PJ, Weltzin JF 2000. Drought Disturbance from Climate Change: Response of the United States Forests. The Science of Total Environment, 262: 205-220.

Keenan SP, Krannig RS 1997. The Social Context of Perceived Drought Vulnerability. Rural Sociology, 62(1): 69-88.

Khazaneh-dari L 1999. Drought crisis. Proceeding of the first conference of investigating of drought solution. Kerman, Jahad-e-Saneshgahi-In press. (in Persian)

Kinsey B, Burger K, Gunning JW 1998. Coping with drought in Zimbabwe: Survey evidence on responses of rural households to risk, World Development, 26(1): P. 89-110.

Kourdovani P 2000. Coping with drought in Iran, Tehran University Press. (In Persian).

Kromker D, Mosler H J 1998. Environment and security: Coping strategies in the face of environmental scarcities. Paper Presented at the 3rd Biennial Conference of the European Society for Ecological Economies. Retrieved January 2003. [Available online at:] http://:/www.wu.wien.ac.at/ csce2000.

Lorena Kenny M 2002. Drought, Clienteles, Fatalism and Fear in Northeast Brazil. Ethics Place and Environment, 5(2): 123 - 134

MacDonnel LJ, Getches DH, Hugenberg WC 1995. The Law of the Colorado River: Coping with Sustained Drought. Water Resources Bulletin, 31(5): 825-836.

Mogadas-Farimani S, Hossaini SM 2004. Pasture ecosystem management in drought. Proceeding of Agricultural Science in Arid Area. Ardestan Azad University press, Iran (in Persian).

Mortimor MJ, Adams WM 2001. Farmer Adaptation, Change and Crisis in the Sahel. Global Environmental Change, 11: 49-57.

Morton J, Sear C 2001. Challenges for drought management in West Asia and North Africa. Paper presented to the Ministerial Meeting on Opportunities for Sustainable Investment in Rain fed Areas of West Asia and North Africa, Rabat, 25-26 May 2001.

Morton J, Barton D, Collinson C, Heath B 2002. Comparing Drought Mitigation Interventions in the Pastoral Livestock Sector. Report to DFID/World Bank, NRI.

Nahavandi-Pour M 2000. Coping with drought. Neday Khamseh Quarterly, 1(1). October, 2000. (In Persian).

Nasajizadeh M 1999. Investigating social, economical and ecological impacts of drought. Proceeding of the First Conference for Drought Crisis Solutions. Zabol University Press, Iran. (in Persian).

Owens T, Hoddinott J, Kinsey B 2003. Ex-ante Actions and Ex-post Public Responses to Drought Shocks: Evidence and Simulations from Zimbabwe. World Development, 31(7): 1239-1255.

Rahmanian D 1999. Coping with drought without planning is impossible. Mahab-Ghods Quarterly, 11(1). (in Persian).

Rockstrom J 2003. Resilience Building and Water Demand Management for Drought Mitigation. Physics and Chemistry of the Earth, 28: 869-877.

Sabet-Rafter A 1999. Investigating Ecological Impacts of Drought. Tehran: Water resources Management Organization.

Salamat A 1999. Coping with drought. Proceeding of the first Conference of Investigating of Drought Solution. Kerman, Jahad -e-Saneshgahi Press, Iran (in Persian).

Sivakumar MVK, Wilhite DA 2002. Drought Preparedness and Drought Management. [Available online at:] http://www.wg-crop.icidonline.org/2doc.pdf

Skoufias E 2003. Economic Crises and Natural Disasters: 
Coping Strategies and Policy Implications. World Development, 31(7): 1087-1102.

Smith M, Munoz G, 2002. Irrigation advisory services for effective water use: a review of experiences. In Proceedings of the FAO-ICID.

Unganai LS 2004. Integrated Drought Management Centre for SSA - A UNESCO supported initiative. Africa Drought Policy Forum, 31 Jan - 2 Feb., 2004, Nairobi, Kenya.

Vogt JV, Somma F 2000. Drought and drought mitigation in Europe. Kluwer Academic Publishers, Dordrecht.

Walter J 2004. World Disasters Report 2004: Focus on Community. Resilience, Kumarian, Bloom field, Connecticut.

Wilhite DA 2000. Drought Preparedness and Mitigation: Moving Towards Risk Management. In: Proceedings of the Central and Eastern European Workshop on Drought Mitigation. Budapest, Hungary, April 12-15.

Wilhite DA, Glantz MH 1985. Understanding the Drought Phenomenon: The Role of Definitions. Water International, 10: 111-120.
Wilhite DA 2000. Drought as a Natural Hazard: Concepts and Definitions (Chapter 1, pp. 3-18). In: DA Wilhite (Ed.): Drought: A Global Assessment (Volume 1), London, U.K: Routledge Publishers.

Yohe G, Burton I, Huq S, Rosegrant MW 2007. Climate Change: Pro-poor Adaptation, Risk Management, and Mitigation Strategies. 2020. Focus Brief on the World's Poor and Hungry People. Washington, DC: IFPRI.

Young RA 1995. Coping with a Severe Sustained Drought on the Colorado River: Introduction and Overview. Water Resources Bulletin, 31(5): 779-788.

Zamani GH, Gorgievski-Duijvesteijn MJ, Zarafshani K 2006. Coping with Drought: Towards a Multilevel Understanding Based on Conservation of Resources Theory. Hum Ecol, 34: 677-692.

Zarafshani K, Zamani GH, Gorgievski-Duijvesteijn MJ 2005. Perceptions and Psychological Coping Strategies of Farmers toward Drought: Implications for Extension Professionals. Journal of Extension Systems, 1(21): 58-71. 